\title{
Tetraspanins: integrating cell surface receptors to functional microdomains in homeostasis and disease
}

\author{
Daniel Kummer ${ }^{1,2} \cdot \operatorname{Tim}_{\text {Steinbacher }}^{1,3} \cdot$ Mariel Flavia Schwietzer $^{1} \cdot$ Sonja Thölmann $^{1} \cdot$ Klaus Ebnet $^{1,2,3,4}$ (i)
}

Received: 20 December 2019 / Accepted: 28 March 2020 / Published online: 9 April 2020

(c) The Author(s) 2020

\begin{abstract}
Tetraspanins comprise a family of proteins embedded in the membrane through four transmembrane domains. One of the most distinctive features of tetraspanins is their ability to interact with other proteins in the membrane using their extracellular, transmembrane and cytoplasmic domains, allowing them to incorporate several proteins into clusters called tetraspaninenriched microdomains. The spatial proximity of signaling proteins and their regulators enables a rapid functional cross-talk between these proteins, which is required for a rapid translation of extracellular signals into intracellular signaling cascades. In this article, we highlight a few examples that illustrate how tetraspanin-mediated interactions between cell surface proteins allow their functional cross-talk to regulate intracellular signaling.
\end{abstract}

Keywords Tetraspanins $\cdot$ Junctional adhesion molecules $\cdot$ Signaling $\cdot$ Microdomains

$\begin{array}{ll}\text { Abbreviations } \\ \text { BCR } & \text { B cell receptor } \\ \text { IgSF } & \text { Immunoglobulin superfamily } \\ \text { JAM-A } & \text { Junctional adhesion molecule-A } \\ \text { TEM } & \text { Tetraspanin-enriched microdomain } \\ \text { TM4SF } & \text { Transmembrane 4 superfamily }\end{array}$

Edited by: Luise Florin.

This article is part of the Special Issue on Tetraspanins in Infection and Immunity.

Klaus Ebnet

ebnetk@uni-muenster.de

1 Institute-Associated Research Group: Cell Adhesion and Cell Polarity, Institute of Medical Biochemistry, ZMBE, University of Münster, Münster, Germany

2 Interdisciplinary Clinical Research Center (IZKF), University of Münster, Münster, Germany

3 Cells-In-Motion Cluster of Excellence (EXC1003-CiM), University of Münster, Münster, Germany

4 Institute of Medical Biochemistry, ZMBE, Von-Esmarch-Str. 56, 48149 Münster, Germany

\section{Introduction}

The translation of extracellular signaling cues into intracellular signaling cascades is frequently mediated by the assembly of signaling complexes at the plasma membrane. Different mechanisms have evolved how these signaling complexes propagate the signals into the interior of the recipient cell. Signaling by G-protein-coupled receptors (GPCRs) is mediated by conformational changes induced by ligand binding resulting in the dissociation of heterotrimeric G-proteins and activation of signaling cascades through the generation of second messengers [1]. Signaling through receptor tyrosine kinases (RTKs) generally involves receptor dimerization as a consequence of ligand binding, which results in a release of the intracellular autoinhibited kinase domain into the active configuration [2]. The consequence of trans-phosphorylation is strongly increased kinase activity, phosphorylation of multiple tyrosine residues, recruitment of adaptor proteins, and assembly of signaling complexes [2].

Signaling events are frequently restricted to specific subcellular sites. This site-specific localization of signaling events can be mediated by physically linking the signaling molecules to cell adhesion receptors present at specific locations, such as sites of cell-matrix adhesion like focal adhesions (FA) [3], or sites of cell-cell adhesion like adherens junctions (AJ) [4], tight junctions (TJ) [5], or synapses [6]. One mechanism underlying the assembly of larger signaling complexes at these sites is the use of scaffolding proteins 
which directly interact with cell adhesion receptors. These scaffolding proteins contain multiple protein-protein interaction domains such as PDZ domains, SH3 domains, or FERM domains [7], allowing them to recruit cytoplasmic signaling proteins at specific sites for functional interactions. One additional mechanism is based on lateral associations of cell adhesion receptors with other integral membrane proteins through linker proteins that are also embedded in the plasma membrane but can interact with several other integral membrane proteins simultaneously. By generating microdomains in the membrane, these lateral associations can promote the assembly of higher order protein complexes.

Tetraspanins (Tspans, also called transmembrane 4 superfamily (TM4SF) proteins), a family of integral membrane proteins consisting of 33 members in humans $[8,9]$, have emerged as bona fide organizers of microdomains in the plasma membrane [10-15]. Tspans contain four $\alpha$-helical transmembrane (TM) regions (TM1-TM4), two extracellular (EC) domains (EC1 and EC2), and three cytoplasmic (CP) regions, (N-terminus, $\mathrm{C}$-terminus and a short loop that connects TM2 and TM3) [10]. These topological domains contribute differently to the structure of tetraspanins and to their ability to undergo intramolecular and intermolecular interactions [15]. The most distinctive feature that qualifies Tspans to organize larger protein complexes in the membrane is their ability to use several of their topological regions of the protein, i.e., the EC domains, the TM domains and the $\mathrm{CP}$ regions for interactions with other proteins $[16,17]$. Of the extracellular domains, EC2 is predominantly involved in heterophilic interactions with other proteins and mainly responsible for the specificities underling these interactions [18]. In addition, the EC2 domain can also mediate tetraspanin dimerization [19]. The TM domains undergo intramolecular interactions that support the functional protein conformation, but they can also mediate homophilic and heterophilic Tspan-Tspan interactions $[15,16,20,21]$. The $\mathrm{CP}$ regions of some Tspan proteins have been found to interact with cytosolic signaling or scaffolding proteins. These include conventional PKCs, which bind to the N-terminal $\mathrm{CP}$ region of CD9 [22], small GTPases like Rac1 which interact with the C-terminal CP region of CD81 [23], and PDZ domain-containing scaffolding proteins like Syntenin-1 or Pick-1, which bind to PDZ domain-binding motifs at the C-termini of CD63 or Tspan7, respectively [24, 25]. The multiple possibilities to interact with other proteins enables Tspans to assemble microdomains or clusters. Tetraspanin clusters cover an area of approximately $100-400 \mathrm{~nm}^{2}$ $[12,15,26,27]$. More recent studies using superresolution microscopy indicate that Tspans form nanoclusters composed of a limited number (less than 10) of selected Tspans with only minor overlaps with other Tspan nanoclusters [15]. The assembly of protein complexes to so-called Tspanenriched microdomains (TEMs) in the plasma membrane is most liklely the principal biological function of Tspans. In this review article, we will present some examples to illustrate the molecular mechanisms through which Tspans exert their function as organizers of signaling complexes during homeostasis and disease with a particular emphasis on their function in connecting immunoglobulin superfamily (IgSF) proteins to other cell surface receptors.

\section{Tspans as linkers between IgSF members and integrins}

\section{Tspans link IgSF family proteins to integrins to regulate angiogenesis}

Angiogenesis describes the formation of new blood vessels from the pre-existing vasculature [28]. It is initiated by proangiogenic factors such as bFGF or VEGF which act on their receptors on endothelial cells to trigger a series of events including the polarization, proliferation and migration of endothelial cells, remodeling of cell-matrix and cell-cell adhesion, and eventually lumen formation [29]. The signaling activities of angiogenic growth factors like bFGF/ FGF2 or VEGF depend in many cases on a specific cooperation with integrins [30]. For example, VEGF-regulated angiogenesis requires a functional $\alpha \mathrm{v} \beta 5$ integrin, whereas bFGF-regulated angiogenesis requires $\alpha v \beta 3$ integrin [31]. The functional coupling of VEGF and bFGF signals to different integrins results in different signaling outcomes [32, 33], suggesting that the physical connection of growth factor receptors or cell adhesion receptors to specific integrins dictates signaling pathways. Recent evidence has identified tetraspanins as linkers between growth factor receptors or adhesion receptors and integrins.

\section{Tspan CD63 links VEGFR2 to $\beta 1$ integrins in endothelial cells}

Tetraspanin CD63 is highly expressed in endothelial cells [34] and interacts with various integrins including $\beta 1$ and $\beta 3$ integrins in primary endothelial cells $[35,36]$. The VEGFR2 has also been found to interact with $\beta 1$ integrins which allows endothelial cells to respond to extracellular matrix-immobilized angiogenic VEGF [37]. Interestingly, CD63 interacts not only with $\beta 1$ and $\beta 3$ integrins but also with VEGFR2 suggesting that it serves to link VEGFR2 to the integrins [36]. Consistent with this notion, CD63 depletion diminishes the association between $\beta 1$ integrin and VEGFR2. CD63 depletion also results in diminished activation of VEGFR2 and in diminished activities of key signaling components present at cell-matrix adhesions such as FAK, Src and Erk1/2 in response to VEGF [36]. These findings strongly suggest that CD63 is required to link VEGFR2 to $\beta 1$ integrin, probably to establish a functional cross-talk 
between activated VEGFR 2 and $\beta 1$ integrin-associated signaling molecules (Fig. 1).

\section{Tspan CD9 links JAM-A to av $\beta 3$ integrin in endothelial cells}

Similar to CD63, tetraspanin CD9 interacts with various integrins including a number of $\beta 1$ and $\beta 3$ integrins, but at the same time with a number of IgSF members [12]. CD9 has also been shown to regulate ERK signaling by modulating ADAM17 protease activity, thereby affecting cellular and pathophysiological processes such as cell migration, wound healing and virus infection [38, 39] (Mikulicic et al. this issue). More recently, CD9 has been identified as an interaction partner of JAM-A [40], a cell adhesion receptor of the IgSF that is expressed by different cell types including endothelial cells [41]. CD9 links JAM-A to $\alpha v \beta 3$ integrin to form a ternary JAM-A-CD9- $\alpha v \beta 3$ integrin complex. Importantly, the depletion of either JAM-A or CD9 impairs bFGFtriggered MAPK activation but has no effect on VEGF-triggered MAPK activation [40], which is in line with previous findings that bFGF cooperates with $\alpha v \beta 3$ integrin in angiogenic signaling [31]. CD9 thus promotes the formation of a bFGF-specific signaling unit in endothelial cells by linking the cell adhesion receptor JAM-A to $\alpha v \beta 3$ integrin. How the bFGF-triggered signal is propagated is less clear. Integrin

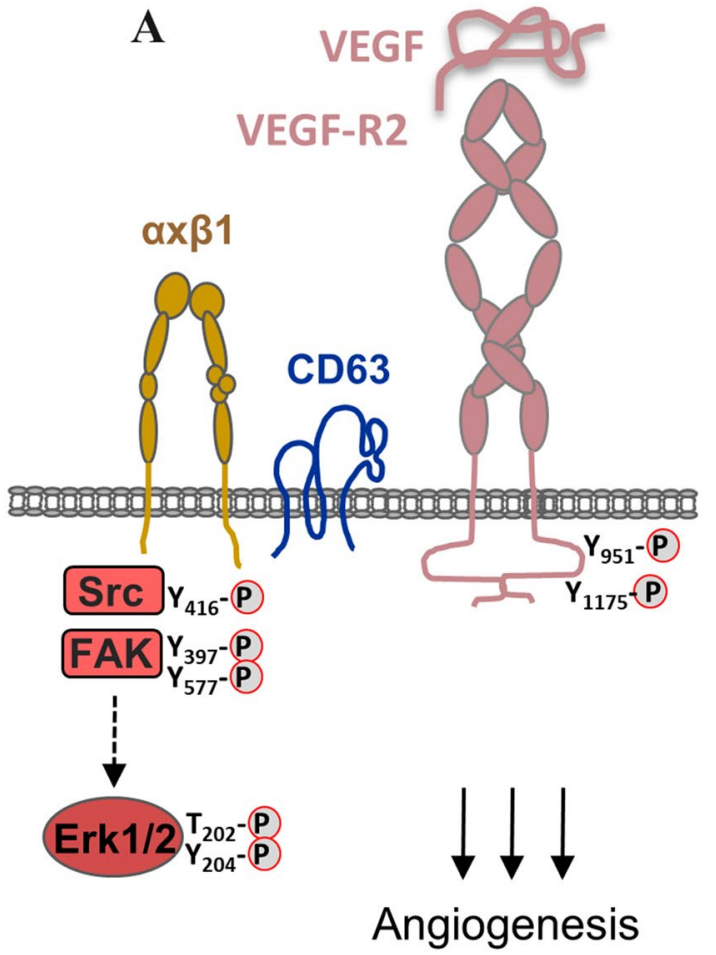

Fig. 1 Regulation of VEGFR2 signaling in endothelial cells by tetraspanin CD63. a Tetraspanin CD63 links $\beta 1$ integrins to VEGFR2 in endothelial cells. VEGF triggers signaling pathways downstream of $\beta 1$ integrin as well as of VEGFR2. b In the absence of CD63, VEGF- activation promotes ternay complex formation suggesting that the open conformation of $\alpha v \beta 3$ integrin more readily interacts with CD9. In contrast, bFGF induces the release of JAM-A from the ternary complex [40, 42] (Fig. 2). This latter observation has been interpreted in a way that preferentially monomeric JAM-A might be incorporated in the complex and that its release induced by bFGF might allow the formation of a signaling-competent dimer [40].

\section{A role for CD9 in linking IgSF proteins to integrins in platelets?}

Tetraspanin CD9 is also expressed on platelets in which it is the most abundant tetraspanin localized at the surface [43]. Among other partners, it interacts with $\alpha \operatorname{IIb} \beta 3$ integrin [44], which is a receptor for fibrinogen and the dominant integrin on platelets [45]. Interestingly, JAM-A has been demonstrated to interact with both CD9 and with $\alpha \operatorname{IIb} \beta 3$ integrin in platelets [46], which suggests that similar to endothelial cells, a ternary JAM-A-CD9- $\beta 3$ integrin complex might exist in platelets. Functional analyses further support the existence of such a ternary complex in platelets. Interestingly, however, this complex seems to play an inhibitory role in platelet activation, which contrasts to its activating function in endothelial cells.

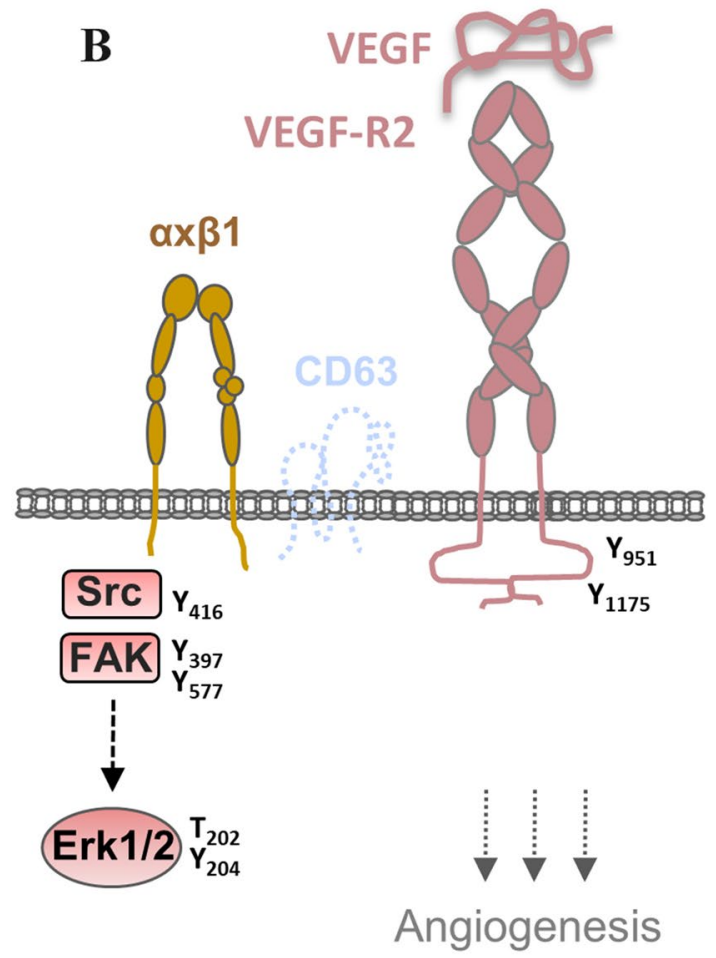

mediated signaling is impaired. Note that the absence of CD63 not only impairs integrin-mediated signaling involving Src, FAK and Erk1/2, but also VEGFR2 phosphorylation 


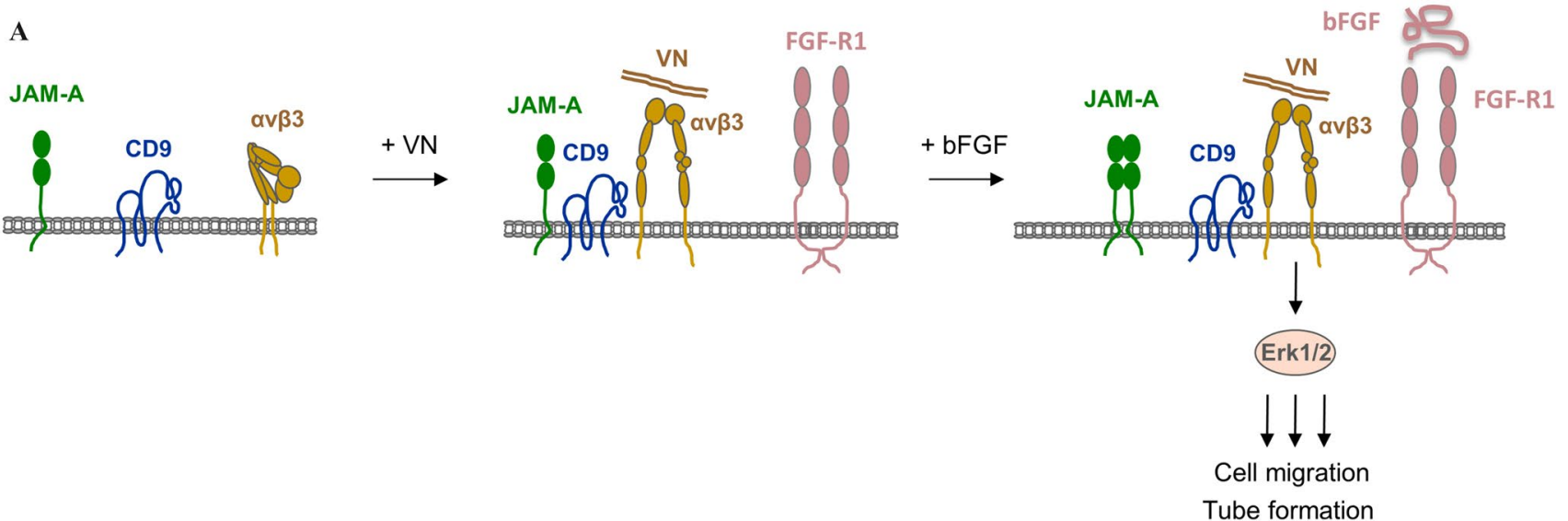

Fig. 2 Regulation of bFGF signaling in endothelial cells by tetraspanin CD9. a Tetraspanin CD9 links cell adhesion molecule JAM-A to $\alpha v \beta 3$ integrin to generate a ternary JAM-A-CD9- $\alpha v \beta 3$ integrin complex. Left panel: Under resting conditions JAM-A, CD9 and $\alpha v \beta 3$ integrin are weakly associated. Middle panel: Integrin activation by

In the absence of CD9, the binding of fibrinogen to stimulated platelets and the inclination to thrombus formation are significantly enhanced, suggesting that CD9 inhibits $\alpha \mathrm{IIb} \beta 3$ integrin-mediated signaling [47]. Similarly, in the absence of JAM-A, platelets are hyperreactive and release significantly more pro-inflammatory chemokines, which is accomapgnied by increased thrombus formation and vascular inflammation $[48,49]$. This inhibitory activity of JAM-A is mediated by the recruitment of the Src-inhibitory kinase Csk to $\alpha \mathrm{IIb} \beta 3$ integrin-associated Src [42]. Given that CD9 and JAM-A have in common an inhibitory function to platelet activation, and that both exist in a complex with $\alpha \operatorname{IIb} \beta 3$ integrin, it is tempting to speculate that CD9 links JAM-A to $\alpha \mathrm{IIb} \beta 3$ integrin to allow a functional interaction of JAM-A-associated Csk with $\alpha \mathrm{IIb} \beta 3$ integrin-associated Src. Thus, CD9 would have the same function in two different cell types, i.e., connecting the IgSF member JAM-A to a $\beta 3$ integrin ( $\alpha v \beta 3$ in endothelial cells, $\alpha \operatorname{Ilb} \beta 3$ integrin in platelets), with, however, different signaling outcomes in the two cell types (Fig. 3).

\section{Tspans link EWI family proteins to integrins to regulate integrin-dependent functions in tumor cells}

Tetraspanins CD9 and CD81 interact with members of a small subfamily of the IgSF of proteins, which is characterized by a conserved Glu-Trp-Ile (EWI) motif. Two members of this family, i.e., EWI motif-containing protein 2 (EWI-2) and EWI-F, have been identified as tetraspanin partners on the basis of their interaction with CD9 and CD81 [50-52]. EWI-2 contains four Ig-like domains, EWI-F contains six Ig-like domains. vitonectin $(\mathrm{VN})$ increases complex formation, probably by promoting lateral association between activated $\alpha v \beta 3$ integrin and CD9. Right panel: bFGF stimulation triggers JAM-A release from the complex concomitant with Erk1/2 activation

The association of CD9 and CD81 with EWI-2 has been characterized in more detail. The interaction of EWI-2 with CD9 and CD81 is most likely direct and mediated by the extracellular domains of the proteins with contribution of the transmembrane domain and Cys residues in the cytoplasmic domain of EWI-2 that are palmitoylated [50, 52, 53]. EWI-2 not only interacts with CD9 and CD81 but also with $\alpha 3 \beta 1$ integrin, which is a receptor for laminin-5, and both CD9 and CD81 can link EWI-2 to $\alpha 3 \beta 1$ integrin [54]. Ectopic expression of EWI-2 impairs the motility of cells on laminin-5, suggesting that EWI-2 influences $\alpha 3 \beta 1$ integrindependent functions [54]. These findings thus indicate that CD9 and CD81 link EWI-2 to a specific integrin, i.e., $\alpha 3 \beta 1$ integrin, to regulate cellular functions that depend on this particular integrin, such as cell migration or scattering of carcinoma cells [55]. The molecular mechanism through which EWI-2 influences these functions are still unexplored.

\section{EWI family proteins regulate Tspan interactions with TGF $\beta$ receptors to regulate receptor signaling}

The regulation of EWI protein interactions with other integral membrane proteins by tetraspanins can be mutual and even occur in a negative manner. As opposed to the recruitment of EWI- 2 to $\alpha 3 \beta 1$ integrin by CD9 and CD 81 to allow functional interaction between EWI-2 and the integrin, the recruitment of CD9 and CD81 to TGF $\beta$ receptors is prevented by EWI-2 to limit TGF $\beta$ signaling [56].

TGF $\beta$ signaling plays a central role during epithelial-tomesenchymal transition (EMT), a process that is critical during development but when inadvertently reactivated in 
A

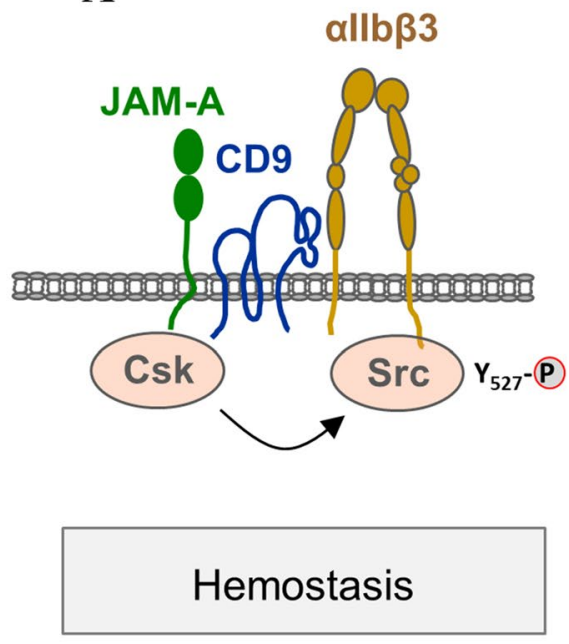

B

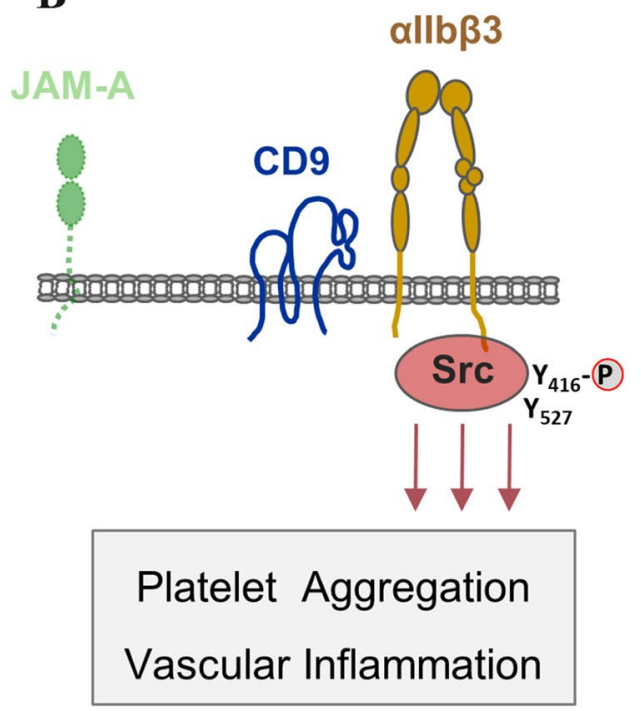

and Src becomes active, which leads to uncontrolled stimulation of Src-dependent signaling pathways. As a consequence, platelets become hyperreactive leading to thrombus formation and vascular inflammation. Similar to endothelial cells, CD9 interacts with both JAM-A and the $\beta 3$ integrin. Note that its function as linker between JAM-A and $\alpha \operatorname{IIb} \beta 3$ integrin has not been proven, yet the adult organism contributes to tumor progression by facilitating invasion and metastasis [57]. TGF $\beta$ signals by inducing hetero-dimerization of two receptors, the Ser/Thr kinases TGF $\beta$ receptor I (T $\beta R I)$ and T $\beta$ RII, resulting in the activation of SMAD proteins, a family of cytoplasmic proteins that form transcriptional complexes which interact with other transcription factors to regulate a plethora of genes [58]. In melanoma cells, TGF $\beta$ signaling contributes to the development of an EMT-like phenotype and to mestasasis [59]. Intriguingly, TGF $\beta$ signaling has different outcomes in melanocytes versus melanoma cells. It has cytostatic effects in melanocytes but promotes proliferation and survival in melanoma cells [60].

A recent study indicates that the tetraspanin partner proteins EWI- 2 negatively regulates TGF $\beta$ signaling, and that EWI-2 regulates TGF $\beta$ signaling activity through CD9 and CD81 [56]. In early stage melanoma cells, when TGF $\beta$ signaling is low, EWI-2 is strongly expressed and interacts with $\mathrm{CD} 9$ and $\mathrm{CD} 81$, thereby sequestering CD9 and CD81 from the TGF $\beta$ receptor complex. However, in later stage melanoma cells when TGF $\beta$ signaling is high, EWI-2 is downregulated, which allows its two tetraspanin partners CD9 and CD81 to engage with TGF $\beta$ receptors and stabilize a signaling active TGF $\beta$ receptor complex resulting in increased Smad signaling [56] (Fig. 4). TGF $\beta$ receptor signaling thus provides a scenario in which tetraspanins are sequestered from a signaling receptor in the plasma membrane by interacting with a tetraspanin binding partner.

\section{Tspans organize nanoclusters of co-receptors to regulate $B$ cell activation upon antigen recognition}

The B cell receptor (BCR) mediates the antigen-specific activation of $\mathrm{B}$-lymphocytes leading to the production of antibodies. The BCR consists of membrane-bound immunoglobulins (Ig) which bind the antigens, and of the noncovalently bound co-receptors CD79A and CD79B (Ig $\alpha$ and $\operatorname{Ig} \beta$, respectively) which form a heterodimer that initiates intracellular signaling [61]. The intracellular signaling is initiated by phosphorylation of ITAM motifs present in the cytoplasmic domains of CD79A and CD79B by Src family kinases (SFK), which leads to an increased association of these kinases with the co-receptors and enhancement of their kinase activity. These initial signals are then propagated by the recruitment of adaptor proteins which recruit additional kinases, adaptors and phospholipases [61].

In the absence of antigens, the BCR is not silent but generates a low strength signal that is required for the survival of mature B cells [62]. Antigen binding amplifies the tonic low strength signal into a strong signal, suggesting 
A

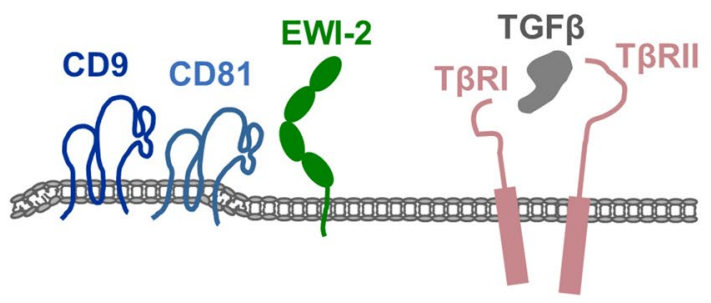

B

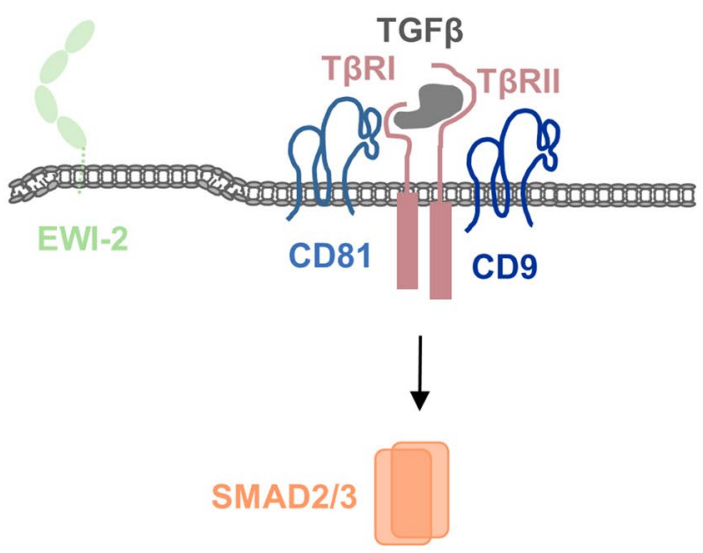

Fig. 4 Regulation of TGF $\beta$ receptor signaling in melanoma cells by tetraspanins CD9 and CD81 and their partner EWI-2. a In early stage, melanoma cells EWI-2 is expressed and interacts with CD9 and CD81. CD9 and CD81 are sequestered from the TGF $\beta$ receptor thereby inhibiting the formation of a functional heterodimeric T $\beta$ RI-

the presence of accessory molecules which serve to increase the signaling capacity of the BCR. One of these accessory molecules is CD19, a single-pass transmembrane protein with two Ig-like domains [63]. CD19 is associated with the BCR and enhances BCR signaling, which is most likely based on its ability to serve as a substrate for SFK and at the same time as a SFK scaffold that promotes SFK activity, and in addition on its ability to regulate PI(3) $\mathrm{K}$ signaling $[64,65]$. Interestingly, CD19 interacts with tetraspanin CD81 $[66,67]$. The interaction with CD81 is necessary for CD19 surface localization [68] but also for the activation of B cells through the BCR [69]. Consistent with this function, the absence of CD81 results in a failure in mounting a humoral immune response [70, 71].

More recent evidence provided a deeper insight into the role of CD81 in regulating BCR signaling through CD19. In resting $\mathrm{B}$ cells, IgM- and IgD-based BCRs as well as CD19 are compartimentalized in nanoclusters at the $\mathrm{B}$ cell surface. Disrupting the actin cytoskeleton results in increased diffusion of $\operatorname{IgM}$ and $\operatorname{IgD}$ nanoclusters triggering cytoskeletondependent BCR signaling. This observation is interpreted in a way that the BCR is kept immobile in a nanocluster and that its diffusibility is required for efficient BCR signaling. Of note, CD19 is organized in a separate nanocluster, and its diffusibility is not dependent on the actin cytoskeleton but on its association with CD81 [69]. In the absence of CD81, CD19 diffusibility is altered, resulting in impaired B cell activation. CD81 thus serves to immobilize CD19 in a nanocluster separate from the BCR nanoclusters. Antigen binding to the $\mathrm{BCR}$ increases $\mathrm{BCR}$ diffusion allowing functional cross-talk with CD19-containing CD81-based nanoclusters, which triggers signal amplification [69]. These
T $\beta$ RII complex. b In later stage melanoma cells, EWI-2 is downregulated allowing CD9 and CD81 to interact with T $\beta$ RII thereby promoting the formation of a signaling-competent TGF $\beta$ receptor. The activation of Smad proteins promotes invasion and metastasis

findings thus highlight a function of tetraspanins in separating co-receptors such as CD19 from primary receptors (i.e., BCRs) to maintain low tonic signaling activity but allow a strong signal amplification by the rapid coalescence of preformed nanoclusters of receptors and their co-receptors (Fig. 5).

\section{Concluding remarks}

One of the most distinctive features of tetraspanins is their ability to associate with other proteins using all of their topological doamins, i.e., their extracellular domains, transmembrane domains and cytoplasmic domains. Together with their ability to undergo homophilic and heterophilic interactions in cis with other tetraspanins, this ability allows tetraspanins to assemble large protein complexes into microdomains. Not surprisingly, tetraspanin-enriched microdomains localized at the plasma membrane are frequently involved in intercellular communication, which requires a rapid assembly of signaling complexes in response to an extracellular signal at a specific subcellular site. Rapid signaling requires close spatial proximity of primary signaling factors, such as growth factor receptors or adhesion receptor-associated signaling molecules, with their regulators. Tetraspanins are ideally suited to assemble protein complexes in which signaling molecules and their regulators are spatially segregated to prevent activation in the absence of agonist but on the other hand are close enough to allow rapid cross-talk in the presence of agonists. Recent observations in other proteinenriched signaling units, i.e., integrin-based adhesion complexes, indicate that signal propagation occurs in the absence 


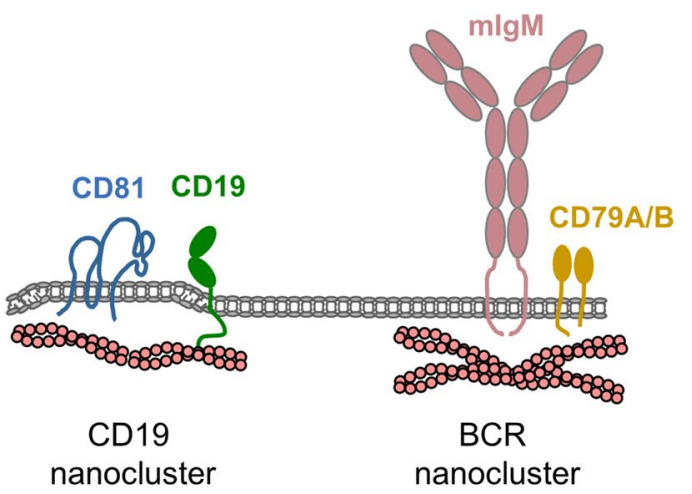

Fig. 5 Regulation of antigen receptor signaling in B cells by tetraspanin CD81. In the absence of antigens, the BCR is organized in nanoclusters regulated by the actin cytoskeleton (left panel). Under these conditions, the BCR provides a tonic, low strength signal required for B cell survival. Binding of antigens to IgM (right panel) triggers

of changes in the composition of the adhesion complex, but is regulated by the relay of phosphotyrosine-dependent signals [72]. As outlined in this review article, tetraspanins can regulate proximity as well as spatial separation of functionally interacting proteins and thus provide the structural framework for rapid regulation of signaling processes. The application of high-resolution imaging techniques that allow single protein tracking will be key to a deeper understanding of the molecular mechanism underlying the function of tetraspanins in development, homeostasis and pathophysiology.

Acknowledgements Open Access funding provided by Projekt DEAL. We wish to thank Volker Gerke for continuous support. This work is supported by grants from the German Research Foundation to K.E. (EB160/7-1, EXC-1003 FF-2016-01) and from the Medical Faculty of the University Münster to K.E. (IZKF Eb2/020/14).

\section{Compliance with ethical standards}

Conflict of interest The authors declare to have no conflict of interest.

Open Access This article is licensed under a Creative Commons Attribution 4.0 International License, which permits use, sharing, adaptation, distribution and reproduction in any medium or format, as long as you give appropriate credit to the original author(s) and the source, provide a link to the Creative Commons licence, and indicate if changes were made. The images or other third party material in this article are included in the article's Creative Commons licence, unless indicated otherwise in a credit line to the material. If material is not included in the article's Creative Commons licence and your intended use is not permitted by statutory regulation or exceeds the permitted use, you will need to obtain permission directly from the copyright holder. To view a copy of this licence, visit http://creativecommons.org/licenses/by/4.0/.

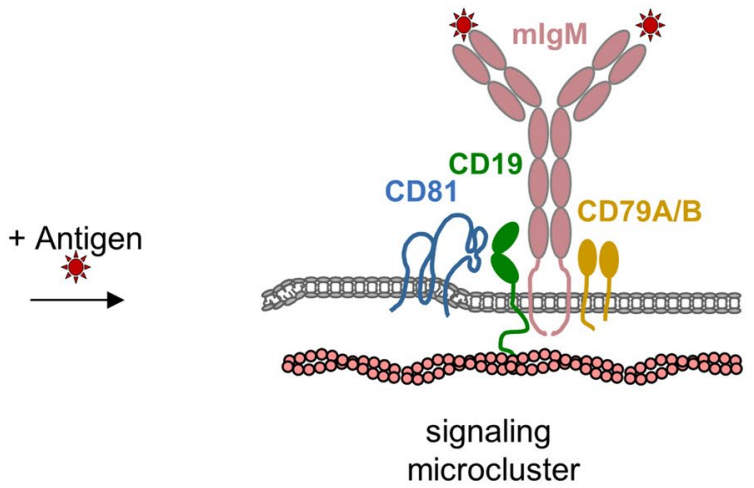

cytoskeletal reorganization that increases the diffusibility of BCRcontaining nanoclusters allowing them to interact with CD19 in CD81-containing nanoclusters, which is necessary for B cell activation and development of effector functions. $m I g M$ membrane-bound $\operatorname{IgM}$

\section{References}

1. Wootten D, Christopoulos A, Marti-Solano M, Babu MM, Sexton PM (2018) Mechanisms of signalling and biased agonism in G protein-coupled receptors. Nat Rev Mol Cell Biol 19(10):638653. https://doi.org/10.1038/s41580-018-0049-3

2. Lemmon MA, Schlessinger J (2010) Cell signaling by receptor tyrosine kinases. Cell 141(7):1117-1134. https://doi. org/10.1016/j.cell.2010.06.011

3. Winograd-Katz SE, Fassler R, Geiger B, Legate KR (2014) The integrin adhesome: from genes and proteins to human disease. Nat Rev Mol Cell Biol 15(4):273-288. https://doi.org/10.1038/nrm37 69

4. Takeichi M (2014) Dynamic contacts: rearranging adherens junctions to drive epithelial remodelling. Nat Rev Mol Cell Biol 15(6):397-410. https://doi.org/10.1038/nrm3802

5. Zihni C, Mills C, Matter K, Balda MS (2016) Tight junctions: from simple barriers to multifunctional molecular gates. Nat Rev Mol Cell Biol 17(9):564-580. https://doi.org/10.1038/ nrm.2016.80

6. Yamada S, Nelson WJ (2007) Synapses: sites of cell recognition, adhesion, and functional specification. Annu Rev Biochem 76:267-294

7. Pawson T, Nash P (2003) Assembly of cell regulatory systems through protein interaction domains. Science 300(5618):445-452

8. Garcia-Espana A, Chung PJ, Sarkar IN, Stiner E, Sun TT, Desalle R (2008) Appearance of new tetraspanin genes during vertebrate evolution. Genomics 91(4):326-334. https://doi. org/10.1016/j.ygeno.2007.12.005

9. Hochheimer N, Sies R, Aschenbrenner AC, Schneider D, Lang $T$ (2019) Classes of non-conventional tetraspanins defined by alternative splicing. Sci Rep 9(1):14075. https://doi. org/10.1038/s41598-019-50267-0

10. Hemler ME (2005) Tetraspanin functions and associated microdomains. Nat Rev Mol Cell Biol 6(10):801-811

11. Levy S, Shoham T (2005) The tetraspanin web modulates immune-signalling complexes. Nat Rev Immunol 5(2):136-148

12. Yanez-Mo M, Barreiro O, Gordon-Alonso M, Sala-Valdes M, Sanchez-Madrid F (2009) Tetraspanin-enriched microdomains: a functional unit in cell plasma membranes. Trends Cell Biol 19(9):434-446. https://doi.org/10.1016/j.tcb.2009.06.004 
13. Charrin S, le Naour F, Silvie O, Milhiet PE, Boucheix C, Rubinstein E (2009) Lateral organization of membrane proteins: tetraspanins spin their web. Biochem J 420(2):133-154

14. Charrin S, Jouannet S, Boucheix C, Rubinstein E (2014) Tetraspanins at a glance. J Cell Sci 127(Pt 17):3641-3648. https:// doi.org/10.1242/jcs. 154906

15. van Deventer SJ, Dunlock VE, van Spriel AB (2017) Molecular interactions shaping the tetraspanin web. Biochem Soc Trans 45(3):741-750. https://doi.org/10.1042/BST20160284

16. Stipp CS, Kolesnikova TV, Hemler ME (2003) Functional domains in tetraspanin proteins. Trends Biochem Sci 28(2):106-112

17. Levy S, Shoham T (2005) Protein-protein interactions in the tetraspanin web. Physiology (Bethesda, Md) 20:218-224

18. Seigneuret M, Delaguillaumie A, Lagaudriere-Gesbert C, Conjeaud $H$ (2001) Structure of the tetraspanin main extracellular domain. A partially conserved fold with a structurally variable domain insertion. J Biol Chem 276(43):40055-40064. https:// doi.org/10.1074/jbc.M105557200

19. Kitadokoro K, Bordo D, Galli G, Petracca R, Falugi F, Abrignani S, Grandi G, Bolognesi M (2001) CD81 extracellular domain 3D structure: insight into the tetraspanin superfamily structural motifs. EMBO J 20(1-2):12-18. https://doi. org/10.1093/emboj/20.1.12

20. Kovalenko OV, Metcalf DG, DeGrado WF, Hemler ME (2005) Structural organization and interactions of transmembrane domains in tetraspanin proteins. BMC Struct Biol 5:11. https:// doi.org/10.1186/1472-6807-5-11

21. Zimmerman B, Kelly B, McMillan BJ, Seegar TCM, Dror RO, Kruse AC, Blacklow SC (2016) Crystal structure of a full-length human tetraspanin reveals a cholesterol-binding pocket. Cell 167(4):1041-1051. https://doi.org/10.1016/j.cell.2016.09.056

22. Zhang XA, Bontrager AL, Hemler ME (2001) Transmembrane-4 superfamily proteins associate with activated protein kinase $\mathrm{C}$ (PKC) and link PKC to specific beta(1) integrins. J Biol Chem 276(27):25005-25013. https://doi.org/10.1074/jbc.M102156200

23. Tejera E, Rocha-Perugini V, Lopez-Martin S, Perez-Hernandez D, Bachir AI, Horwitz AR, Vazquez J, Sanchez-Madrid F, YanezMo M (2013) CD81 regulates cell migration through its association with Rac GTPase. Mol Biol Cell 24(3):261-273. https://doi. org/10.1091/mbc.E12-09-0642

24. Latysheva N, Muratov G, Rajesh S, Padgett M, Hotchin NA, Overduin M, Berditchevski F (2006) Syntenin-1 is a new component of tetraspanin-enriched microdomains: mechanisms and consequences of the interaction of syntenin-1 with CD63. Mol Cell Biol 26(20):7707-7718

25. Bassani S, Cingolani LA, Valnegri P, Folci A, Zapata J, Gianfelice A, Sala C, Goda Y, Passafaro M (2012) The X-linked intellectual disability protein TSPAN7 regulates excitatory synapse development and AMPAR trafficking. Neuron 73(6):1143-1158. https:// doi.org/10.1016/j.neuron.2012.01.021

26. Nydegger S, Khurana S, Krementsov DN, Foti M, Thali M (2006) Mapping of tetraspanin-enriched microdomains that can function as gateways for HIV-1. J Cell Biol 173(5):795-807. https://doi. org/10.1083/jcb.200508165

27. Termini CM, Cotter ML, Marjon KD, Buranda T, Lidke KA, Gillette JM (2014) The membrane scaffold CD82 regulates cell adhesion by altering alpha4 integrin stability and molecular density. Mol Biol Cell 25(10):1560-1573. https://doi.org/10.1091/mbc. E13-11-0660

28. Adams RH, Alitalo K (2007) Molecular regulation of angiogenesis and lymphangiogenesis. Nat Rev Mol Cell Biol 8(6):464-478. https://doi.org/10.1038/nrm2183
29. Potente M, Gerhardt H, Carmeliet P (2011) Basic and therapeutic aspects of angiogenesis. Cell 146(6):873-887. https://doi. org/10.1016/j.cell.2011.08.039

30. Weis SM, Cheresh DA (2011) alphav integrins in angiogenesis and cancer. Cold Spring Harbor Perspect Med 1(1):a006478

31. Friedlander M, Brooks PC, Shaffer RW, Kincaid CM, Varner JA, Cheresh DA (1995) Definition of two angiogenic pathways by distinct alpha $v$ integrins. Science 270(5241):1500-1502

32. Hood JD, Frausto R, Kiosses WB, Schwartz MA, Cheresh DA (2003) Differential alphav integrin-mediated Ras-ERK signaling during two pathways of angiogenesis. J Cell Biol 162(5):933-943

33. Alavi A, Hood JD, Frausto R, Stupack DG, Cheresh DA (2003) Role of Raf in vascular protection from distinct apoptotic stimuli. Science 301(5629):94-96

34. Bailey RL, Herbert JM, Khan K, Heath VL, Bicknell R, Tomlinson MG (2011) The emerging role of tetraspanin microdomains on endothelial cells. Biochem Soc Trans 39(6):1667-1673. https ://doi.org/10.1042/BST20110745

35. Takawale A, Zhang P, Patel VB, Wang X, Oudit G, Kassiri Z (2017) Tissue inhibitor of matrix metalloproteinase-1 promotes myocardial fibrosis by mediating CD63-integrin beta1 interaction. Hypertension 69(6):1092-1103. https://doi.org/10.1161/HYPER TENSIONAHA.117.09045

36. Tugues S, Honjo S, Konig C, Padhan N, Kroon J, Gualandi L, Li X, Barkefors I, Thijssen VL, Griffioen AW, Claesson-Welsh L (2013) Tetraspanin CD63 promotes vascular endothelial growth factor receptor 2-beta1 integrin complex formation, thereby regulating activation and downstream signaling in endothelial cells in vitro and in vivo. J Biol Chem 288(26):19060-19071. https:// doi.org/10.1074/jbc.M113.468199

37. Chen TT, Luque A, Lee S, Anderson SM, Segura T, Iruela-Arispe ML (2010) Anchorage of VEGF to the extracellular matrix conveys differential signaling responses to endothelial cells. J Cell Biol 188(4):595-609. https://doi.org/10.1083/jcb.200906044

38. Gutierrez-Lopez MD, Gilsanz A, Yanez-Mo M, Ovalle S, Lafuente EM, Dominguez C, Monk PN, Gonzalez-Alvaro I, Sanchez-Madrid F, Cabanas C (2011) The sheddase activity of ADAM17/TACE is regulated by the tetraspanin CD9. Cell Mol Life Sci 68(19):3275-3292

39. Liu J, Zhu G, Jia N, Wang W, Wang Y, Yin M, Jiang X, Huang Y, Zhang J (2019) CD9 regulates keratinocyte migration by negatively modulating the sheddase activity of ADAM17. Int J Biol Sci 15(2):493-506. https://doi.org/10.7150/ijbs.29404

40. Peddibhotla SS, Brinkmann BF, Kummer D, Tuncay H, Nakayama M, Adams RH, Gerke V, Ebnet K (2013) Tetraspanin CD9 links junctional adhesion molecule-A to alphavbeta3 integrin to mediate basic fibroblast growth factor-specific angiogenic signaling. Mol Biol Cell 24(7):933-944. https://doi.org/10.1091/mbc.E12-06-0481

41. Ebnet K (2017) Junctional adhesion molecules (JAMs): cell adhesion receptors with pleiotropic functions in cell physiology and development. Physiol Rev 97(4):1529-1554. https://doi. org/10.1152/physrev.00004.2017

42. Naik MU, Caplan JL, Naik UP (2014) Junctional adhesion molecule-A suppresses platelet integrin alphallbbeta3 signaling by recruiting Csk to the integrin-c-Src complex. Blood 123(9):13931402. https://doi.org/10.1182/blood-2013-04-496232

43. Zhang F, Kotha J, Jennings LK, Zhang XA (2009) Tetraspanins and vascular functions. Cardiovasc Res 83(1):7-15. https://doi. org/10.1093/cvr/cvp080

44. Indig FE, Diaz-Gonzalez F, Ginsberg MH (1997) Analysis of the tetraspanin CD9-integrin alphaIIbbeta3 (GPIIb-IIIa) complex in platelet membranes and transfected cells. Biochem J 327(Pt 1):291-298

45. Huang J, Li X, Shi X, Zhu M, Wang J, Huang S, Huang X, Wang H, Li L, Deng H, Zhou Y, Mao J, Long Z, Ma Z, Ye W, Pan J, Xi 
X, Jin J (2019) Platelet integrin alphaIIbbeta3: signal transduction, regulation, and its therapeutic targeting. J Hematol Oncol 12(1):26. https://doi.org/10.1186/s13045-019-0709-6

46. Sobocka MB, Sobocki T, Babinska A, Hartwig JH, Li M, Ehrlich YH, Kornecki E (2004) Signaling pathways of the F11 receptor (F11R; a.k.a. JAM-1, JAM-A) in human platelets: F11R dimerization, phosphorylation and complex formation with the integrin GPIIIa. J Recept Signal Transduct Res 24(1-2):85-105

47. Mangin PH, Kleitz L, Boucheix C, Gachet C, Lanza F (2009) CD9 negatively regulates integrin alphaIIbbeta3 activation and could thus prevent excessive platelet recruitment at sites of vascular injury. J Thromb Haemost 7(5):900-902

48. Karshovska E, Zhao Z, Blanchet X, Schmitt MM, Bidzhekov K, Soehnlein O, von Hundelshausen P, Mattheij NJ, Cosemans JM, Megens RT, Koeppel TA, Schober A, Hackeng TM, Weber C, Koenen RR (2015) Hyperreactivity of junctional adhesion molecule a-deficient platelets accelerates atherosclerosis in hyperlipidemic mice. Circ Res 116(4):587-599. https://doi.org/10.1161/ CIRCRESAHA.116.304035

49. Naik MU, Stalker TJ, Brass LF, Naik UP (2012) JAM-A protects from thrombosis by suppressing integrin alphaIIbbeta3-dependent outside-in signaling in platelets. Blood 119(14):3352-3360

50. Stipp CS, Kolesnikova TV, Hemler ME (2001) EWI-2 is a major CD9 and CD81 partner and member of a novel Ig protein subfamily. J Biol Chem 276(44):40545-40554

51. Stipp CS, Orlicky D, Hemler ME (2001) FPRP, a major, highly stoichiometric, highly specific CD81- and CD9-associated protein. J Biol Chem 276(7):4853-4862. https://doi.org/10.1074/jbc. M009859200

52. Clark KL, Zeng Z, Langford AL, Bowen SM, Todd SC (2001) PGRL is a major CD81-associated protein on lymphocytes and distinguishes a new family of cell surface proteins. J Immunol 167(9):5115-5121

53. Montpellier C, Tews BA, Poitrimole J, Rocha-Perugini V, D'Arienzo V, Potel J, Zhang XA, Rubinstein E, Dubuisson J, Cocquerel L (2011) Interacting regions of CD81 and two of its partners, EWI-2 and EWI-2wint, and their effect on hepatitis C virus infection. J Biol Chem 286(16):13954-13965. https://doi. org/10.1074/jbc.M111.220103

54. Stipp CS, Kolesnikova TV, Hemler ME (2003) EWI-2 regulates alpha3beta1 integrin-dependent cell functions on laminin-5. J Cell Biol 163(5):1167-1177

55. Kawano K, Kantak SS, Murai M, Yao CC, Kramer RH (2001) Integrin alpha3beta1 engagement disrupts intercellular adhesion. Exp Cell Res 262(2):180-196. https://doi.org/10.1006/ excr.2000.5083

56. Wang HX, Sharma C, Knoblich K, Granter SR, Hemler ME (2015) EWI-2 negatively regulates TGF-beta signaling leading to altered melanoma growth and metastasis. Cell Res 25(3):370-385. https://doi.org/10.1038/cr.2015.17

57. Pei D, Shu X, Gassama-Diagne A, Thiery JP (2019) Mesenchymal-epithelial transition in development and reprogramming. Nat Cell Biol 21(1):44-53. https://doi.org/10.1038/s4155 6-018-0195-Z

58. Massague J (2012) TGFbeta signalling in context. Nat Rev Mol Cell Biol 13(10):616-630. https://doi.org/10.1038/nrm3434

59. Paluncic J, Kovacevic Z, Jansson PJ, Kalinowski D, Merlot AM, Huang ML, Lok HC, Sahni S, Lane DJ, Richardson DR (2016) Roads to melanoma: Key pathways and emerging players in melanoma progression and oncogenic signaling. Biochem Biophys Acta 1863 4:770-784. https://doi.org/10.1016/j.bbamc r.2016.01.025
60. Perrot CY, Javelaud D, Mauviel A (2013) Insights into the transforming growth factor-beta signaling pathway in cutaneous melanoma. Ann Dermatol 25(2):135-144. https://doi.org/10.5021/ ad.2013.25.2.135

61. Packard TA, Cambier JC (2013) B lymphocyte antigen receptor signaling: initiation, amplification, and regulation. F1000Prime Rep 5:40. https://doi.org/10.12703/P5-40

62. Srinivasan L, Sasaki Y, Calado DP, Zhang B, Paik JH, DePinho RA, Kutok JL, Kearney JF, Otipoby KL, Rajewsky K (2009) PI3 kinase signals BCR-dependent mature B cell survival. Cell 139(3):573-586. https://doi.org/10.1016/j.cell.2009.08.041

63. Wang K, Wei G, Liu D (2012) CD19: a biomarker for B cell development, lymphoma diagnosis and therapy. Exp Hematol Oncol 1(1):36. https://doi.org/10.1186/2162-3619-1-36

64. Fujimoto M, Fujimoto Y, Poe JC, Jansen PJ, Lowell CA, DeFranco AL, Tedder TF (2000) CD19 regulates Src family protein tyrosine kinase activation in B lymphocytes through processive amplification. Immunity 13(1):47-57. https://doi.org/10.1016/s1074 -7613(00)00007-8

65. Burger JA, Wiestner A (2018) Targeting B cell receptor signalling in cancer: preclinical and clinical advances. Nat Rev Cancer 18(3):148-167. https://doi.org/10.1038/nrc.2017.121

66. Horvath G, Serru V, Clay D, Billard M, Boucheix C, Rubinstein E (1998) CD19 is linked to the integrin-associated tetraspans CD9, CD81, and CD82. J Biol Chem 273(46):30537-30543. https://doi. org/10.1074/jbc.273.46.30537

67. Cherukuri A, Shoham T, Sohn HW, Levy S, Brooks S, Carter R, Pierce SK (2004) The tetraspanin CD81 is necessary for partitioning of coligated CD19/CD21-B cell antigen receptor complexes into signaling-active lipid rafts. J Immunol 172(1):370-380. https ://doi.org/10.4049/jimmunol.172.1.370

68. Tsitsikov EN, Gutierrez-Ramos JC, Geha RS (1997) Impaired CD19 expression and signaling, enhanced antibody response to type II T independent antigen and reduction of B-1 cells in CD81deficient mice. Proc Natl Acad Sci USA 94(20):10844-10849. https://doi.org/10.1073/pnas.94.20.10844

69. Mattila PK, Feest C, Depoil D, Treanor B, Montaner B, Otipoby KL, Carter R, Justement LB, Bruckbauer A, Batista FD (2013) The actin and tetraspanin networks organize receptor nanoclusters to regulate $\mathrm{B}$ cell receptor-mediated signaling. Immunity 38(3):461-474. https://doi.org/10.1016/j.immuni.2012.11.019

70. Maecker HT, Levy S (1997) Normal lymphocyte development but delayed humoral immune response in CD81-null mice. J Exp Med 185(8):1505-1510. https://doi.org/10.1084/jem.185.8.1505

71. van Zelm MC, Smet J, Adams B, Mascart F, Schandene L, Janssen F, Ferster A, Kuo CC, Levy S, van Dongen JJ, van der Burg M (2010) CD81 gene defect in humans disrupts CD19 complex formation and leads to antibody deficiency. J Clin Investig 120(4):1265-1274. https://doi.org/10.1172/JCI39748

72. Horton ER, Humphries JD, Stutchbury B, Jacquemet G, Ballestrem C, Barry ST, Humphries MJ (2016) Modulation of FAK and Src adhesion signaling occurs independently of adhesion complex composition. J Cell Biol 212(3):349-364. https://doi.org/10.1083/ jcb.201508080

Publisher's Note Springer Nature remains neutral with regard to jurisdictional claims in published maps and institutional affiliations. 